\title{
Ambient air quality and human health: Current concepts Part 1
}

\author{
TEE L GUIDOTTI MD MPH FRCPC CCBOM \\ Department of Public Health Sciences, University of Alberta Faculty of Medicine, \\ Edmonton, Alberta
}

TL GUIDOTTI. Ambient air quality and human health: Current concepts, Part 1. Can Respir J 1995;2(4):211222.

There is a fundamental reevaluation of the association between air quality and human health taking place. This reevaluation is motivated by several recent developments: increasing interest in air quality as an environmental issue; interest in the unanswered questions regarding the epidemiology of asthma; and the reduced prevalence of the principal hazard to respiratory health, cigarette smoking, the control of which invites interest in second-order determinants of health. This article attempts to provide a framcwork for understanding air quality issues that pertain to human health. The objective is to provide the specialist in respiratory medicinc with an overvicw that will assist in educating patients and in responding to their inquiries, and to equip the physician to respond to requests for assistance or interpretation when called upon to comment on public policy issues involving air pollution. The implications of setting air quality standards or objectives to meet arbitrary levels of risk of health effects are examined. The current state of the art does not support risk-based air quality standards. A policy of continuous improvement is most protective of both human health and the environment.

Key Words: Air pollution. Air alualits. llechlth

\section{Qualité de l'air ambiant et santé des humains : Notions courantes - Première partie}

RÉSUMÉ : On procède actuellement à une révituation fondamentale de l'association entre la qualité de l'air et la santé des humains. Cette réévaluation est motivée par plusieurs faits récents tels qu'un intérêt accru pour la qualité de l'air comme question environnementale, un intérêt pour les problèmes non résolus en matière d'épidémiologie de l'asthme et, la diminution de la prévalence du principal risque pour la santé respiratoire, le tabagisme, (tont le contrôle convie à s'intéresser aux déterminants de la santé de seconde catégorie. Cet article essaie de fournir un cadre propice a) la comprćhension des questions en matière de qualité de l'air ayant un rapport avec la santé des humanns. L'objectif est de fournir au spécialiste en maladies respiratoires une vue d'ensemble qui lui servira pour éduquer ses palients et répondre à leurs questions, et de préparer le médecin à faire face aux demandes d'aide ou d'explications sur la politique publique en matière de pollution atmosphérique. Les conséquences de l'établissement de normes de qualité de l'air ou d'objectifs pour satisfaire des niveaux de risque arbitraires sont examinées. Actuellement, les résultats des recherches les plus élaborées ne sont pas en faveur de normes sur la qualité de l'air basées sur le risque. Line politique d'amélioration continue s'avère une meilleure protection it la fois pour la santé des humains et pour l'environnement.

Correspondence and reprints: Depurtment of Public Hewhl Sciences, University of Alberta Faculty of Medicinc. 1.3-103 Clinical Sciences Building, Edmonton. Alhorta T6G 2G3. Telephonc 403-492-6291. Fax 403-492-0364. e-mail Tee.Guidotti(a uallorta.ca 


\section{A} IR QUALITY IS UNDERGOING A RE-EVALUATION AS A RISK factor for human disease. On a scientific level, this renewed interest is evident in the intense interest and discussion that centres on the effects of small particulates (the so-called 'PM 10 fraction', or particulates below the cutoff of the respirable range of $10 \mu \mathrm{m})$, the relationship between ozone and asthma, and recent studies documenting health effects in extreme situations in developing countries and countries of the former Soviet Union and Warsaw Pact $(1,2)$. In Canada, this increased activity is manifested by voluntary multistakeholder programs such as the industry-sponsored Accelerated Reduction/Elimination of Toxics (ARET) program, which deals with air and other media, government initiatives such as the $\mathrm{NO}_{\mathrm{x}} /$ VOC Management Plan and the federal Green Plan for a Healthy Environment, and a series of recent initiatives linking air quality and energy policy, including the 1993 Comprehensive Air Quality Framework for Canada. There also seems to be increasing activity on air quality issues on the provincial and local levels, especially the ambitious multistakeholder Clean Air Strategic Alliance: in Alberta.

This level of activity on air quality issues was not evident just five years ago. A common thread seems to be that air quality is not so visibly separated from other environmental health concerns as in years past. As well, there seems to be an increasing emphasis on documenting the cost of the effects of exposure 10 air pollution compared with the cost of air quality management, a trend particularly evident in the case of $\mathrm{PM}_{10}$. Another trend, not documented in the literature but evident from observation of numerous hearings and public meetings, is that the issue of air pollution appears to be fused in the public's mind with that of the perceived increase in frequency of asthma and mortality from the disease.

There appears to be a difference in perception on either side of the border with respect to ambient air quality as an environmental issue. In a 1992 survey conducted for Health Canada, Slovic et al (3) ranked various health risks as perceived by Canadians. 'Outdoor' air quality, as a survey item, showed a paradoxical response. Although it was one of the lower ranked health risks for which respondents attributed a 'high' health risk (20\%), it was one of the more highly ranked risks for which respondents attributed a 'moderate' risk (approximately $50 \%$ ). 'Indoor' air quality showed a similar pattern, although it was less highly ranked as a high health risk. However, other items that incorporated air quality issues, particularly 'ozone depletion', 'chemical pollution' and 'climate change', were ranked much higher (4). This suggests, but does not in itself prove, that the Canadian public now sees air quality less as a particular, well-defined issue and more as an aspect of a much greater issue involving chemical pollution, environmental health and ecosystem stability. By contrast, American jurisdictions as diverse as California and Vermont have ranked ambient air quality among the environmental issues of greatest health risk to residents in risk comparison projects, and have done so separately and in addition to more aggregated categories of environmental risk $(5,6)$. This suggests that Americans continue to see ambient air quality as a relatively discreet issue. The difference may reflect differences in the perceived severity of urban air pollution in the major centres of each country.

The renewed emphasis on air quality issues suggests that it may be timely to review current concepts on air pollution and human health effects, particularly for the benefit of physicians who may find themselves in a position of responding to questions or educating the public. A review of the topic may also be useful in shaping clinical judgements about what is and what is not likely to be a response to air pollution in a particular patient, something that is very difficult to say with certainty.

\section{BACKGROUND}

In the 1950 s and $1960 \mathrm{~s}$, the identification of outdoor, or 'ambient', air quality as a possible risk factor for respiratory disease initiated a new field of investigation in air quality studies (7-12). This led to a series of studies on human health effects of exposure to air pollutants, the most extensive of which were known collectively as the Community Health and Environmental Surveillance System (CHESS) studies, to be discussed in greater detail in part 2 . The studies conducted during that era remain the basis for most American ambient air quality standards and many Canadian air quality guidelines. Exceptions are the standards for ozone, which were based on human experimental studies after an initial standard for total oxidants, based on epidemiological data, and $\mathrm{PM}_{10}$, which was revised from an earlier standard for total suspended particulates dating from this era, in part because of epidemiological evidence that the $\mathrm{PM}_{10}$ fraction was more important than total particulates including those of larger size (13).

The first United States legislation dealing with air pollution was passed in 1955 (14). The Clean Air Act was passed in 1963, amended in 1970 and has been modified several times since. The 1970 amendments, which gave responsibility for administering the Act to the then-new Environmental Protection Agency, began a process of general continual improvement that lasted for over a decade. Until about 1982 , there was substantial progress in controlling air pollution, particularly total suspended particulates (the first to come under reasonable control nationally in the United States) and oxides of sulphur. Less progress was made with photochemical oxidants during this period. A National Commission on Air Quality convened in 1981 concluded that, although the overall gains in air quality were more modest than had been expected, the significant effect of the Clean Air Act had been to keep the situation from getting much worse (15). However, the worst problems seemed to be localized to only a few large urban centres, in particular Los Angeles, New York, Philadelphia, Chicago, Denver and the Ohio River Valley. Within a few years, however, air pollution levels, particularly oxides of nitrogen and carbon monoxide, were again increasing in major metropolitan areas of North America as a consequence of increased numbers of vehicles on the road, despite improved control of emissions from individual vehicles (16). During the $1980 \mathrm{~s}$, little further progress seems to have been 
made in the United States towards tighter regulation because of competing political priorities. One exception has been Los Angeles, which has made substantial progress in reducing oxidant levels from previous levels (17). However, that city continues to have, despite its progress, the most refractory air quality problem in the United States.

In the early ycars the Canadian problem seemed to be almost trivial compared with that in the United States. However, there were early voices of concern. Bates (18) was among the first to consider the implications of air quality studies for Canada, particularly in a widely circulated book entitled A Citizen's Guide to Air Pollution. Lacking data on pollutant levels and personal exposure in Canadian centres, Bates drew inferences from the United Kingdom and the United States in an effort to describe what might have been happening in Canada. Bates also drew attention to Swedish models as porhaps having relevance to the problem in Canada. He observed at the time that "For every physician concerned about ... air pollution, there are maybe 50 biologists whose interest relates to the conservation of wildlife and the possible long term effects of detergents and pesticides on the countryside and the animals it supports. This has had the effect of diverting attention away from human problems, and deserves some correction."

Parliament passed the Clean Air Act in 1971, putting this country on track for reduction of emissions. Canadian provinces, however, have primary jurisdiction on environmental issues, and they enacted ambient air quality standards of their own, more or less in concert, in the ensuing years. The federal government retained authority in emissions of specific toxic substances (so-called 'air toxics') and fuel composition (19).

Air pollution levels did generally decline in Canadian cities in the early 1970s (when most were at or near the current maximum acceptable guidelines), especially levels of sulphur dioxide and suspended particulates, but total oxidants showed little change or even increased in southern Ontario; nitrogen dioxide began and stayed relatively low $(20,21)$. This trend tapered off in the later 1970 s in most cities except Montreal. Not surprisingly, given the source of emissions, particulates and sulphur dioxide predominated in the East and oxidants generally in the West, although oxidants were a problem in Toronto and were noted to be increasing in Hamilton $(20)$. At the time, there was also evidence that acute respiratory illness was associated with air quality in Hamilton (22). Other cities may have shown similar effects had they been studied (22).

Subsequently, indoor air quality became a major public health issue in the 1980 s (23), seemingly eclipsing ambient air quality for a while. The declining rate of cigarette smoking seems to have thrown some attention on nonsmokingrelated risk factors. As the primary determinant of respiratory health comes under increasing control, investigators are invited to give their attention to other controllable health risks as a strategy for making further improvements.

Several recent developments have contributed to the renewed recognition of air quality as a public health issue. One is a series of landmark studies conducted by Bates and col- leagues in the late 1980s demonstrating an association between increased frequency of hospital admissions, many for asthmatic episodes, and sulphur dioxide or airborne sulphate in southern Ontario (24) and Vancouver (25). This observation coincided with the demonstration of increasing mortality from asthma in many countries (not necessarily Canada) (26) and suggested a plausible association with increasing levels of air pollution. There soon followed a series of studies from Holland linking episodes of asthma with exposure to ozone $(27,28)$. Most recently, the outstanding example of air quality-related health research in North America - the Six Cities Study - reported that exposure to airborne particulates of respirable size was associated with mortality (29). All of this activity has contributed a sense of urgency to air quality issues.

The Canadian Smog Advisory Program is a cooperative federal and provincial program designed to monitor and advise on implications and policy in nonattainment areas. It may advise a health alert (as occurred once in Toronto in 1994) and may devise indicators to monitor progress. It is most active in the Windsor-Quebec corridor but is expected to extend its activities soon to British Columbia.

The current situation in Canada is highly variable among regions. In general, ambient ozone is the most common exceedence and episodes in excess of the one-hour maximum acceptable objective are most common in the Windsor-Quebec corridor, the Saint John area and the lower Fraser Valley. The highest frequency of exceedences involving ozone in Canada coincide with concentrations of vehicular traffic and of the petrochemical industry, ie, in Windsor, Sarnia, Toronto and Montreal $(30,31)$. Because ozone is a secondary air pollutant produced from photochemical reactions involving hydrocarbons and oxides of nitrogen, the key to controlling ozone is to control volatile hydrocarbon emissions and emissions of oxides of nitrogen.

Many recent developments have affected the management of air quality and policy initiatives on the part of federal and provincial governments. On a political level, the federal government targeted air quality in the Green Plan for a Healthy Environment (1991) and developed its ' $\mathrm{NO}_{\mathrm{x}} / \mathrm{VOCs}$ ' strategy in 1990 to control emissions of oxides of nitrogen $\left(\mathrm{NO}_{\mathrm{x}}\right)$ and volatile organic compounds (VOCs) and, by doing so, to control atmospheric levels of ozone (30-32).

Among the provinces, Alberta has demonstrated particular concem over the issue because of its role as a leading energy exporting province with a heavy economic stake in matters directly related to air quality, such as fossil fuels and public transportation policy. In Alberta, interest in air quality includes ambient air quality, sour gas and hydrogen sulphide emissions, acid deposition and hazardous air pollutants ("air toxics', which are understood to mean any potentially hazardous chemical that may be emitted to air and that is not covered by an existing air quality guideline). A provincial initiative in the late 1970 s and early 1980 s called the Acid Deposition Research Program (ADRP) sponsored a great deal of useful scientific work on air quality. There was no immediate successor to ADRP, but in 1990 a new mechanism was set up to deal with unresolved issues. The Clean Air 
Strategic Alliance of Alberta (formerly the Clean Air Strategy of Alberta) is a government-industry partnership designed to address air quality issues in the province. As well, the Energy Resources Conservation Board has been particularly active in addressing issues of accidental release of hydrogen sulphide from sour gas development. There has always been concern in the province over point-source emissions of hazardous air pollutants, particularly hydrogen sulphide from sour gas development.

\section{AIR QUALITY}

Air quality is more than a statement regarding the extent of air pollution at a given time. Air quality is also a judgement regarding both the effects that we perceive and effects that act below the threshold of human perception but that may affect the ecosystem and so indirectly affect human life.

Public policy discussions regarding air quality tend to equate the term with simple concentrations of air pollution and are usually dominated by concerns over human health. l lowever, for many air pollutants, particularly the oxidants and airborne acid-forming chemicals, the direct effects of air pollution on vegetation and freshwater biola are proportionately much greater than those demonstrated on human health. Many effects of air pollution tend to act over prolonged periods or are consequences of repeated exposure. Air quality must therefore be described in terms of relevant time intervals, not just as instantaneous descriptions of levels of air poliutants. Air quality can also be perceived as a description of an end-point achieved by the action of numerous variables, some of them difficult to quantify, that are responsible for detcmining the final chemical state of the air we breathe.

One way to approach the interpretation of air quality is to compare it with an ideal state of "clean air".

What is 'clean air"? A particularly useful definition of clean air has been developed by a working group of the Clean Air Strategy for Alberta (now the Clean Air Strategic Alliance) in order to achieve consensus and a reasonable working vocabulary among representatives of government, industry and the public (33):

'Clean air' is represented by air that is essentially odourless, tasteless, looks clear and has no measurable short-or longterm adverse effects on people, animals and the environment.

This definition makes several distinctions that are important from the standpoint of public policy and air quality management. One is that clean air is a socially agreed upon objective with definable characteristics, not an absolute or scientilically definable state of chemical purity. Clean air approximates the natural state of the atmosphere free of human interference or exceptional natural emissions (as by fire or volcanic cruption). This definition is a response to a point of view common in regulatory and public policy debates, that clean air is basically an atmosphere that does not exceed air pollution standards.

This point of view is increasingly out of touch with the public's environmental awareness, which expects progress lowards cleaner air and reflects concern over current levels of air pollution, regardless of what may be permitted by air quality guidelines.

It follows from this definition of clean air that 'dirty air", or air pollution, is any significant deviation from this state of clean air as a result of human activity. This concept comes close to the view held by the general public, which seems to be growing increasingly impatient with reassurances that health problens cannot be linked to obvious pollution levels. Some authorities speak of air pollution as any degradation in quality causing an adverse effect or loss of utility to humankind, whether the cause is human activity or natural, noncatastrophic processes, such as plant-derived emissions or (distant) volcanic eruption. However, this definition is problematic in air quality studies because natural background variation is uncontrollable, may exceed levels attributable to human activity and is the natural state in which the local ecosystem evolved in the first place.

Air pollution can be defined as follows: the emission into the air or the production of chemically active compounds at a rate that exceeds the capacity of natural processes to convert or dissipate them. This is a specific application of a more general definition of pollution (34). Air pollution affects health when these compounds accumulate to concentrations capable of producing a biologically significant effect. Unfortunately, the 'loading capacity' of the environment is exceedingly difficult to measure, and the critical rates of emission that result in accumulation can only be estimated. Also, not all significant pollutants are emitted to air - some of the most important (such as ozone and nitrogen dioxide) are secondary pollutants generated by chemical reactions in the atmosphere.

Measuring air pollutants: As mentioned above, air quality is more than a simple description of the concentration of air pollutants at a given time. However, the measurement of air pollution is a critical part of the description of air quality. Only by identifying the concentration, trends in time and distribution of air pollutants is it possible to design effective strategies for the control of emissions from sources of air pollution.

Only a small number of chemicals known to be present in the atmosphere as air pollutants are actually measured by most agencies responsible for environmental regulation. The cost of measuring trace levels of minor air pollutants is very large and the additional monitoring capacity is not usually worth the additional expense. Instead, air pollution monitoring tends to rely on these basic principles: first, air pollutants tend to go up and down together in a predictable way - it is usually not necessary to measure benz(a)pyrene directly, for exaniple, if one knows the ambient hydrocarbon levels; second, accurate measurement of individual chemicals at a particular time is usually much less important than trends over time - the monitoring technology has therefore been developed for continuous monitoring, not for automated detailed analysis: and third, human health effects are generally attributable to a small number of air pollutants that are among the "primary pollutants" measured routinely. This assumption 
was incorrect in the case of lead, which was not originally a primary pollutant.

Air pollution monitoring takes two general forms: monitoring of ambient air quality and surveillance of particular emissions sources. The technology for each is generally different. Monitoring ambient air quality is fundamentally a problem of detecting dilute concentrations of particulates or gases in a complex atmosphere; the principal concerns are precision, not accuracy, and documenting trends over time. Surveillance of particular emissions sources, on the other hand, involves detection of much greater concentrations but requires greater quantification to allow the calculation of the mass of emissions from a particular stack or vehicle; the principal concerns are accuracy and extrapolation of daily or annual emissions. Ambient air quality monitoring will be discussed first (16,35).

The technology of ambient air quality monitoring has become quite sophisticated in recent years but it still relies on a set of instruments in tandem sampling the atmosphere and recording the results electronically, allowing quick calculation of mean concentrations over relevant periods (typically an hour, a day, or a year). These means are then compared with existing air quality standards or (in the case of Canada) guidelines. If the observed mean is greater, there has been an 'exceedence'. In the past, observed levels below the standard or guideline have been dismissed as inconsequential, but in recent years increasing public interest in air quality and increasing scientific criticism of the basis of standards has drawn more attention to the absolute levels of air pollution, not just levels relative to an arbitrary standard.

Particulates are typically sampled today by passing air through a filter and reported by count or weight of particles, as total suspended particulates. Increasingly, air quality monitoring agencies are also reporting the concentration of particulates below the cutoff of the respirable range of $10 \mu \mathrm{m}$ (the so-called 'PM10' fraction), because of the relative importance of this fraction in human health. Historically, there were many other methods for measuring ambient particulate levels. Most are now obsolete, but the most important was a method used in the United Kingdom in the early years of air pollution studies, called the British Standard Method, or 'British smoke'. This involved a sampler using much slower flow rates than American 'high-vol' technology and was presumed at the time to be a more accurate reflection of particulates in the respirable range because the larger particles were removed gravimetrically.

The technologies used for monitoring gaseous air pollutants are determined by the chemistry of the air pollutant. Carbon monoxide is easy to measure because the gas absorbs light in the infrared range; it can be measured continuously with an infrared spectrophotometer designed for the purpose. Highly chemically reactive air pollutants, such as ozone and oxides of nitrogen, are also relatively easy to measure continuously; both of these chemicals are monitored by chemiluminescence, a method that detects light emitted when the atmosphere is introduced into a chamber with a reactant gas. Sulphur oxides, on the other hand, are more difficult 10 monitor by continuous methods. There are two common methods of measurement for sulphur oxides. The "tetrachloromercurate absorber/pararosaniline' method measures total sulphur components $\left(\mathrm{SO}_{\mathrm{x}}\right)$. The more recent method of chromatographic separation with flame photometric detection, which is also known as 'pulse florescence', separates individual sulphur compounds, including hydrogen sulphide, and is preferred for continuous monitoring. Advances in air monitoring of sulphur compounds have made it practical to investigate health effects associated with the predominant sulphur species in the atmosphere rather than assuming that all the effect is due to sulphur dioxide.

Source monitoring, or emissions surveillance, on the other hand, is performed primarily for regulatory purposes in support of protecting ambient air quality. Because the concentrations of air pollutants are typically much greater at the source, less sensitive but more accurate methods can be used. Sanıpling typically involves introducing a probe into a stack or an exhaust pipe and obtaining a sample over a relatively short period of time; this is called a 'grab sample'. The sample may then be analyzed by a variety of wet chemical methods (36) or, increasingly, by highly accurate methods such as mass spectroscopy or flame ion spectrophotometry.

Remote monitoring of air pollution sources is becoming increasingly useful due to advances in technology. The primary application of these methods so far has been in monitoring acid deposition and air mass movements over long distances by satellite. However, it may soon become practical for local air quality agencies to conduct surveillance of sources quite accurately from a distance and to do so routinely. One example of a 'low tech' application of remote surveillance is the use of a 'Ringelmann chart', which is a set of printed grids against which the density of thick smoke plumes can be compared visually and ranked by their opacity as a surrogate measure of particulate density.

Summary indexes of air quality have been developed in order to reduce a complicated profile of air pollutant concentrations, variable over time, to a single derived number or panel of numbers. The intention has been to simplify presentation of air quality trends in order to facilitate monitoring, public education and making policy decisions. One problem with summary indexes of air quality is that they usually are difficult to relate to adverse health consequences because they are normally based on air quality standards, not toxicity levels. An example is Environment Canada's "Index of the Quality of Air' (IQUA), which is a summary scale from 0 to 125 used to communicate air quality information to the public. The IQUA is based on National Ambient Air Quality Objectives and trends are based on the summation of all five (37). It is not used in setting public policy or monitoring air quality trends in response to control measures. Despite considerable attention to the problem and ingenuity in constructing indexes, air quality indexes have not figured prominently in most management schemes.

An alternative approach, at least for public awareness, has been the use of 'smog alerts' (38). These have been most useful in areas of intense air pollution, such as southern 


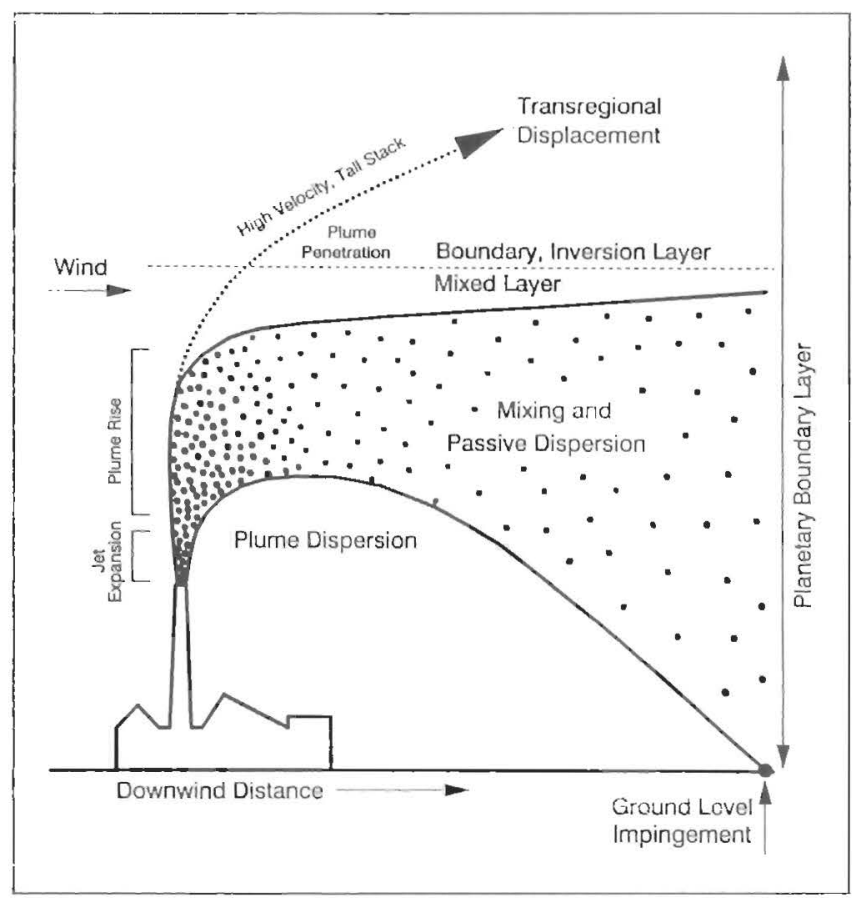

Figure 1) A simple case of atmospheric dispersion from a stationary source. The downwind ground-level concentration of a pollutant at the point where the plume hits the ground and beyond can be

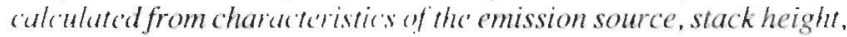
whitude reached by the plum', wind syeed and horizontal distan's'

California, where periodic alerts seem to have a reinforcing effect on public awareness. Alert levels are typically based on some notion of adverse health consequences and are accompanied by health advisory notices, usually advising people to stay indoors or to avoid exercising out of doors. In most jurisdictions where alerts are in use, such as Los Angeles, they are driven almost entirely by oxidant levels.

Determinants of air quality: As noted above, air quality is more than the final concentration of air pollutants at a given point in time. However, to appreciate the complexities of air quality it is necessary first to understand the factors governing the dispersion of airbornc emissions.

The accumulation of chemically active compounds in the atmosphere is greatly affected by land features and by atmospheric movements. Valleys, closed-in mountain ranges, and lack of open space (parks, forests, wilderness areas, bodies of water) strongly increase the severity of air pollution in a given locale. These features hold the air mass like a container and prevent dilution and mixing. Stagnant air masses may receive emissions for days on end. When winds are calm, a thermal layer of warmer air may sit on an air mass like a lid on a jar and prevent its movement. This is called a 'subsidence inversion'. Inversions are situations where the temperature of air increases with altitude rather than decreases, as is usually the case in the troposphere. Subsidence inversions are common almost everywhere but tend to be frequent and long lasting only in a few areas, principally in narrow river valleys or the seacoast and over large bodies of water. The combination of high population density, concentrated emissions sources, enclosure by mountains and frequent inversions explain why air pollution has been a particular problem in valleys and basins (39), such as the greater Vancouver area and the Fraser Valley and on the shore of inland lakes, as in the case of Hamilton and Toronto (20). These same factors explain why southern California has a particularly severe problem of air quality.

The dispersion of air pollutants from a single source and the behaviour of air pollutants in a given airshed can both be mathematically modelled by computer models of greater or lesser complexity (40). The most familiar such model used in western Canada is called 'Gascon 2'. It is used principally to model the probable behaviour of a plume of gas escaping from a sour gas well or pipeline leak.

Figure 1 describes the situation in a typical, simple emission from a stationary source to the atmosphere. $A$ jet of (usually) warm air escapes from the stack at a certain velocity and is displaced by wind, and the plume describes a distorted cone with one side constrained by the inversion layer and the other by impingement at ground level, where air pollution is detectable on the ground. Within the cone (plume) there is mixing and dilution over distance. The higher the stack or the stronger the wind, the longer the distance until the plume touches ground and the more dilute it will be. In the absence of wind, the plume will rise and spread under the inversion layer until it dissipates. An exceptionally strong wind can cause turbulence and a 'downwash' that brings the plume down to ground level for short periods. Sources close to the ground, such as brush fires or motor vehicles, will contribute to pollution at ground level, especially if the inversion layer is low. Under other conditions, air pollution modelling be-comes extremely complicated (40) and is beyond the scope of this article.

It is a mistake to think of air quality narrowly in terms of air pollution levels and to treat air pollution control as primarily a problem in engineering and chemistry. Air pollution levels at a given time are the result of these many factors acting on the combined emissions from stationary and mobile sources, with local distortions introduced by topography and wind patterns. However, air quality in general also takes into consideration the changes in air pollution levels over time, the direction of exposure at given levels, the effects of exposure on the natural ecosystem and human health, the effects of exposure on the local economy and agriculture, and the forces set into play for the abatement of air pollution. The latter brings into the equation a list of behavioural factors and affects collective level of concern and understanding in the society producing and affected by air pollution. Air pollution is the product of social activities, the result largely of economic activity and transportation planning. Air pollution control and the maintenance of air quality is likewise a social process, involving education, the perception of accidents. economic costs and political will.

Figures 2 through 5 build a conceptual model of air quality in keeping with the broader view of the problem. Figure 2 presents the first step in a general conceptual model of air quality. The airshed is defincel by the topographic features of 


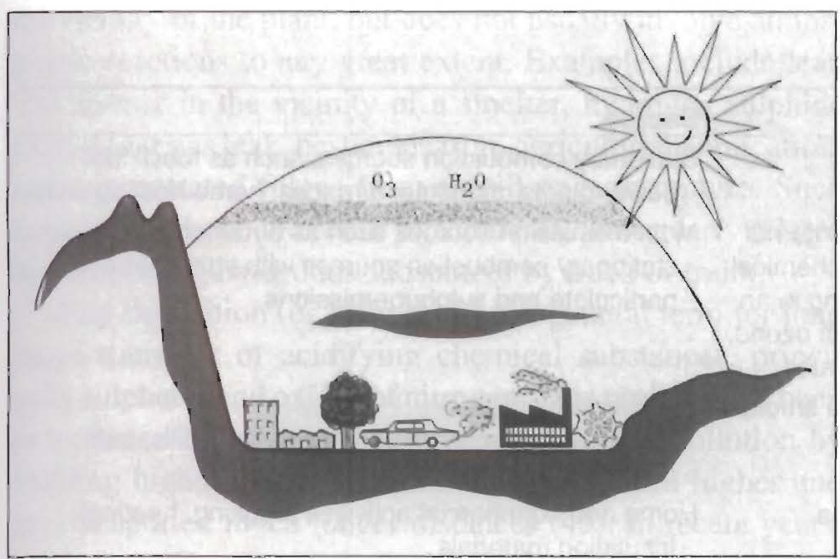

Figure 2) Step I in a conceptual model of air quality. Mobile and stationary sources of emission release pollutants into the airshed. which is confined horizontally by topographic features and vertically by the height of the inversion layer. The accumulated primary air pollutants are acted upon by sunlight, driving photochemical reactions to form secondary pollutants. (Modified from an original drawing by Iolun $R$ Goldsmith)

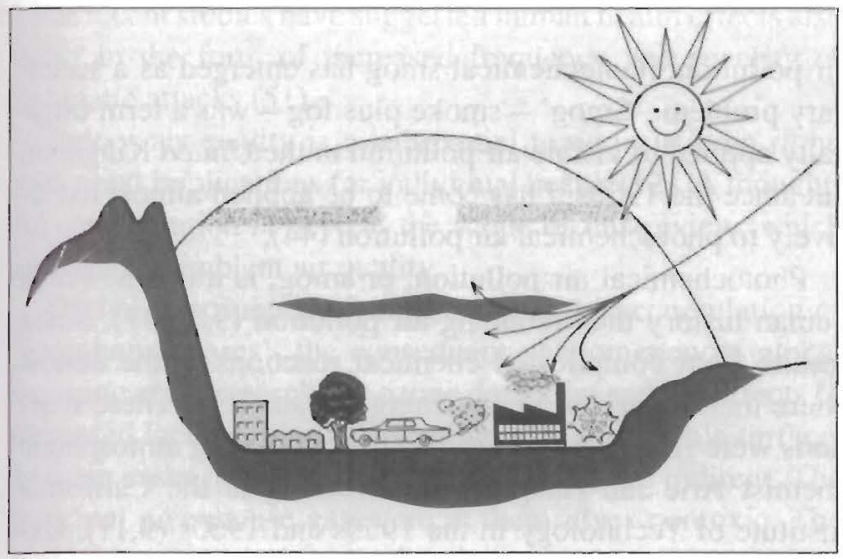

Figure 3) Step 2 in a conceptual model of air quality. Dilution of both primary and secondary air pollutants occurs within the volume of the air mass. Wind redistributes the pollutants and promotes mixing. (Modified from an original drawing by, ollm $R$ Goldsmith)

the region and the atmosphere above it. The space that defines the potential volume of air mixing is confined horizontally by topographic features and vertically by the height of the inversion layer. Mobile and stationary sources of emission release pollutants into the airshed. The accumulated primary air pollutants are acted upon by sunlight, driving photochemical reactions that form secondary pollutants. The second step (Figure 3 ) is mixing and dilution of both primary and secondary air pollutants within the volume of the air mass, greatly accelerated by higher wind velocities. The third step (Figure 4) in the conceptual model of air quality is documentation of the effects of exposure. Health risks, ecosystem damage and materials degradation as a result of exposure to air pollutants are observed, and regional concentrations of air pollutants are monitored. Time and variation in concentration became critical variables in determining the effects of exposure on the natural ecosystem, the economy, agriculture and human heilth.

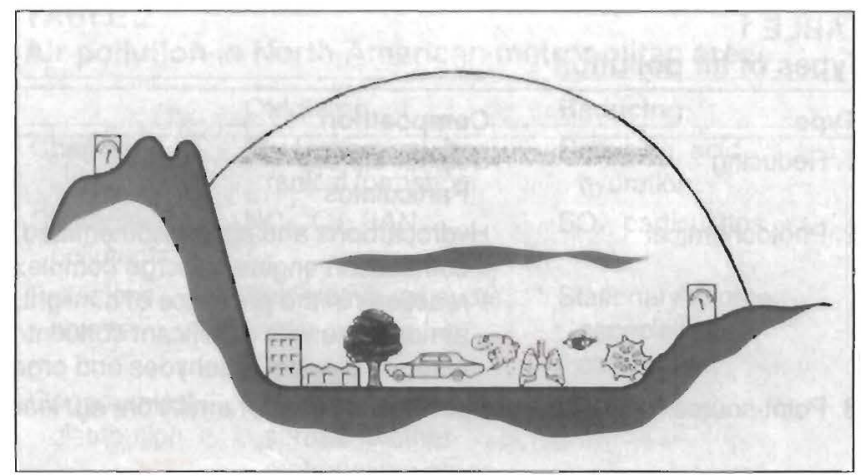

Figure 4) Step in a conceptual model of air quality. Effects of exposure to air pollutants are observed and regional concentrations are monitored. Time and variation in concentration become critical variables in controlling the effects on the natural ecosystem, the economy, agriculture and human health. (Modified from an original drawing by John $R$ (ioldsmith)

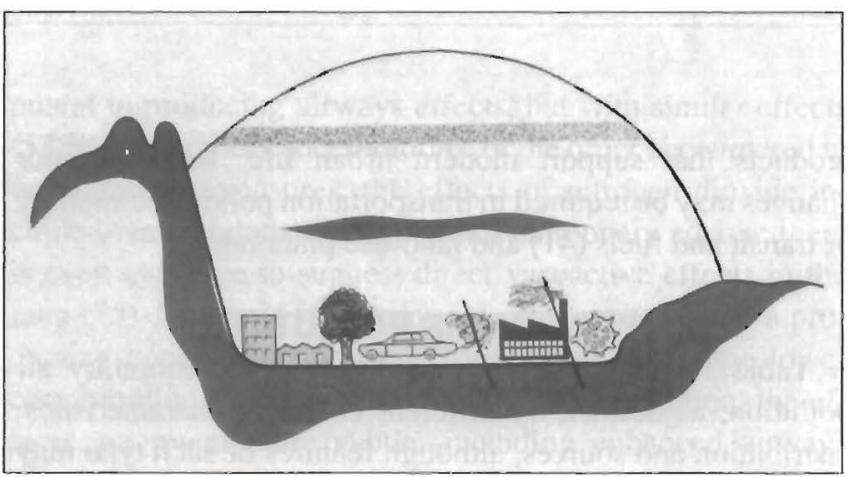

Figure 5) Step 4 in a conceptual model of air quality. Individual and collective behavioural change, through public policy, economic incentives, engineering controls and change in individual lifestyle such as acceptance of public transportation. Air quality improvement is driven by cost, perception, education, and public concern translated into political will and economic incentives in the marketplace. (Modified from an original drawing by Johm $R$ (

Thus far, the conceptual model has been physical and chemical. To understand fully the implications of air pollution and to return to the definition of clean air advanced above, a social dimension needs to be factored into the fourth step (Figure 5). When costs become apparent and esthetic values are impaired, there is a social response, facilitated by research and education. The social response is manifested through public policy, economic incentives, engineering controls and education. Air quality improvement is driven by cost, perception, education and public concern translated into political will and economic incentives in the marketplace. Individual behaviour changes, as in the choice of whether to drive or take the bus or walk to a near destination. However, individual change alone cannot be relied upon to achieve clean air because the individual lives in a complex society in which alternatives for transportation and power are not always readily available, and there is little that the individual can do about the production and distribution of energy and 


\section{TABLE 1}

\section{Types of air pollution}

\section{Type}

1. Reducing

2. Photochemical

3. Point-source

4. Indoor

5. Acıd deposition

6. 'Greenhouse gases' and ozone depletion

\section{Composition}

Sulphur dioxide Particulates

Hydrocarbons and nitric oxide emitted by the internal combustion engine undergo complex photochemical reactions in the presence of sunlight, resulting in an atmosphere with significant concentrations of ozone nitrogen dioxide, aldehydes and organic nitrates

Specific to source of emission, eg, lead near a smelter

Specific to source, eg, formaldehyde, asbestos. nitrogen dioxide

Sulphates, nitrogen oxides

Carbon dioxide, methane, water vapour. chiorofluorocarbons

\section{Source}

Stationary combustion sources, such as fossil fuel power plants, industrial furnaces, home heating units

Mobile emission sources such as automobiles, stationary combustion sources with tight control of particulate and sulphur emissions

\section{Specific industries}

Industrial or transportation accidents (spills, train derailments)

Home and commercial activities (cooking, heating) Insulation materials

Furnishings

Cigarette smoke

Same as 1 and 2

Transported over long distances and may cause environmental effects or, possibly, health effects

Most human activity, including industry and agriculture products that support modern urban life. Rather, major changes may be required in transportation policy, technology of transit and fuels (41) and land-usc planning.

\section{TYPES OF AIR POLLUTION}

Table I compares six general types of community air pollution, as defined by different chemical characteristics, distribution and sources, although features of each type may be present to varying degrees in any given community's air pollution.

Reducing, or 'acid', air pollution is caused by the emission of sulphur dioxide and particulates, which act as chemical reducing agents in the atmosphere (42). This is by far the oldest type of air pollution, characterized as 'fumifugium' by John Evelyn in 17th-century London. This type of air pollution was responsible for most of the early air pollution catastrophes and for the infamous London 'particulars' or 'pca-soupers', which were occasionally lethal combinations of smoke and fog that occurred up to the late 1950s (43). Emissions of sulphur dioxide are caused by burning fossil fuels that contain some sulphur; emissions of particulates occur most heavily when combustion is inefficient. Reducing air pollution is produced primarily by stationary combustion sources, such as fossil fuel power plants, industrial furnaces and home heating units. Typical concentrations of air pollutants are higher in reducing air pollution than in other types, and there is a strong link with acid deposition when this type of air pollution is transported long distances. Reducing air pollution was characteristic in the past of older areas of industrial concentration, particularly in steel manufacturing centres such as Hamilton. This type of air pollution is relatively easy to control with conventional engineering controls. It remains a serious problem in developing countries, particularly China.

As cities in developed countries have controlled reducing air pollution, photochemical smog has emerged as a secondary problem. 'Smog' - smoke plus fog - was a term originally applied to visible air pollution in the United Kingdom, but since the 1950s it has come to be applied almost exclusively to photochemical air pollution (44).

Photochemical air pollution, or smog, is much newer in human history than reducing air pollution $(9,45-47)$. Smog results from complicated chemical reactions in the atmosphere that are driven by the energy in sunlight. These reactions were first characterized by the pioneering atmospheric chemist Arie Jan Haagen-Smit, working at the California Institute of Technology in the 1950s and 1960s (9,11). Oxides of nitrogen produced by combustion and hydrocarbons undergo reactions to produce ozone, specific secondary reaction products of nitrogen, and aldehydes, all of which are highly reactive and chemically oxidizing. Smog is caused primarily by emissions from mobile sources, overwhelmingly automobiles, but it is exacerbated by certain types of emissions from stationary sources, such as hydrocarbons from refineries, evaporated gasoline and dry cleaning solvents, and oxides of nitrogen from power plants (43). Because of the need for sunlight to drive these chemical reactions and because of local reliance on the automobile for transportation, photochemical air pollution appeared first in the cities of the American sunbelt, especially Los Angeles, but soon appeared in the northeast region as well (48). This type of air pollution has become much more common in developed countries such as Canada, regardless of local concentrations of industry or climate.

Table 2 compares the characteristics of reducing and oxidizing or photochemical air pollution.

A third type of community air pollution is point-source emissions. Industrial activities or accidents may release a relatively large quantity locally or a particular type of air pollution that becomes a local problem affecting the immedi- 
ate vicinity of the plant, but does not usually involve atmospheric reactions to any great extent. Examples include lead and arsenic in the vicinity of a smelter, hydrogen sulphide from a sour gas leak, pesticides from agricultural application, and concentrated fumes from a spill or tank rupture. Such emissions may be the result of accidents, particularly related to transporting hazardous substances by truck or train.

Acid deposition (or 'acid rain') is a general term for long range transport of acidifying chemical substances, principally sulphates and oxides of nitrogen. This problem has been exacerbated by efforts to control ground-level pollution by building higher stacks; the pollutants rise much higher and are transported much longer distances (49). In recent years, with more effective control of sulphur emissions, oxides of nitrogen have become increasingly more important in acid deposition. Acid deposition is an international problem, as emissions from the American Midwest travel freely over Canada, and emissions from Germany and Central Europe fall on Scandinavia. The principal disturbances caused by acid deposition appear to be ecological, with acidification of lakes and effects on sensitive species of trees (50). However, some recent studies have suggested human health effects also occur in the form of increased frequency and severity of asthmatic attacks (51).

Indoor air quality is a substantial topic in its own right, with great implications for individual health (52). A thoughtful consideration is beyond the scope of this review, which emphasizes ambient air quality.

Global atmospheric changes include the accumulation of 'greenhouse gases', the consequent phenomenon of global warming and stratospheric ozone depletion and the effects of increased incident ultraviolet radiation at the Earth's surface. In these cases, the effects on human health are indirect. The principal greenhouse gases are in themselves nontoxic. The problems associated with global warming pertain more to changing climate, with implications for agriculture and vector distribution, and chiotic weather conditions. Likewise, the chlorofluorocarbons that are primarily responsible for reduction of the protective ozone layer in the lower stratosphere have very low intrinsic toxicity, but increased incident ultraviolet radiation may lead to increased incidence of skin cancers and possibly immune effects. These issues are beyond the scope of this review but are discussed in detail elsewhere (49).

\section{TOXICOLOGY OF AIR POLLUTANTS}

The toxicology of air pollution is exceedingly complex. There are different types of air pollution, many different pollutants and great variation in individual susceptibility to their effects at low, environmentally relevant concentrations. Generally speaking, the toxicological characteristics of most chemicals at high concentrations are irrelevant to their behaviour and effects as air pollutants. Air pollution is therefore best approached as a unique toxicological problem of complex mixtures at low concentrations.

For example, nitrogen dioxide is an oxidant gas, about a 10 th as potent as ozone in causing bronchiolitis, and less
TABLE 2

Air pollution in North American metropolitan areas

\begin{tabular}{|c|c|c|}
\hline & Oxidizing & Reducing \\
\hline Chemistry & $\begin{array}{l}\text { Photochemical, free } \\
\text { radical formation }\end{array}$ & $\begin{array}{l}\text { Reducing, acid } \\
\text { hydration }\end{array}$ \\
\hline $\begin{array}{l}\text { Characteristic } \\
\text { pollutants }\end{array}$ & $\mathrm{NO}_{x}, \mathrm{O}_{3}, \mathrm{PAN}$ & $\mathrm{SO}_{x}$, particulates \\
\hline $\begin{array}{l}\text { Emissions } \\
\text { source }\end{array}$ & Automotive exhausts & $\begin{array}{l}\text { Stationary source, } \\
\text { especially coal } \\
\text { combustion }\end{array}$ \\
\hline $\begin{array}{l}\text { Geographical } \\
\text { distribution }\end{array}$ & $\begin{array}{l}\text { Sunbelt, but also } \\
\text { spread to other } \\
\text { metropolitan areas } \\
\text { with control of } \\
\text { reducing air pollution }\end{array}$ & Northeast \\
\hline $\begin{array}{l}\text { Primary control } \\
\text { strategy }\end{array}$ & $\begin{array}{l}\text { Catalytic converter } \\
\text { (automobiles) } \\
\text { Transportation policy }\end{array}$ & $\begin{array}{l}\text { Retrofit of stationary } \\
\text { sources }\end{array}$ \\
\hline $\begin{array}{l}\text { Meteorological } \\
\text { conditions }\end{array}$ & $\begin{array}{l}\text { Sunlight, atmospheric } \\
\text { inversions }\end{array}$ & $\begin{array}{l}\text { Fog, atmospheric } \\
\text { inversions }\end{array}$ \\
\hline
\end{tabular}

NO. Oxides of nitrogen; PAN Peroxyacetyl nitrate; $\mathrm{SO}_{x}$ Oxides of sulphur

potent in producing airways effects, but with similar effects $(53,54)$. At higher concentrations, of the order encountered in occupational exposures, the effects of nitrogen dioxide include severe endothelial injury and puImonary edema; there is even evidence to suggest direct vasoactive effects in the lung (55). Systemic symptoms are often reported and a productive cough is not unusual (56). However, at the lower concentrations encountered in ambient air pollution, the etfects are much more subtle, including enhanced airways reactivity and compromised host defences in the respiratory tract $(54,57)$. In cell culture, pretreatment with $\mathrm{N}$-acetylcysteine (a precursor to glutathione, which increases intracellular antioxidant capacity) reduces cytotoxicity after exposure to nitrogen dioxide (58). There is also evidence that pretreatment by ingestion of supplemental ascorbic acid prevents the expression of airways hyperresponsiveness in normal subjects after exposure to nitrogen dioxide, in a time frame too quick to be due to oxidant injury secondary to inflammation (59). These findings suggest that effects at both levels are mediated directly by the oxidant properties of nitrogen diox ide but are concentration-dependent. In short, the chemical properties of this, and all other, air pollutants define their toxicity, but the effects observed at low concentrations characteristic of ambient air quality are not necessarily the same or weaker versions of the same effects anticipated at high level exposures (60).

The inhalation toxicology of air pollutants is extremcly difficult to study technically. There are relatively few laboratories in North America equipped to handle inhalation exposures at relatively low concentrations. In Canada, the principal laboratories for this type of work are at the Bureau of Chemical Hazards in Ottawa, the Gage Institute in Toronto and the Alberta Environment Centre in Vegreville.

Air pollution of the reducing variety has been studied since the 1930s. The major constituents of photochemical air pollution have been extensively studied at environmental 
TABLE 3

Known health effects of individual air pollutants

\begin{tabular}{|c|c|c|}
\hline & Effects of environmentally relevant concentrations & Contributing or potentiating factors \\
\hline Sulphur dioxide & $\begin{array}{l}\text { Airways irritation, bronchitis, bronchoconstriction, provocation of } \\
\text { asthmatic episodes }\end{array}$ & Exercise particulates, asthma \\
\hline Nitrogen dioxide & $\begin{array}{l}\text { Mild airways irritation, cough, reduced airflow, bronchiolitis, reduced } \\
\text { host defences }\end{array}$ & Exercise, respiratory tract infection, asthma \\
\hline Ozone & $\begin{array}{l}\text { Airways irritation, provocation of asthmatic episodes, chest tightness, } \\
\text { cough, reduced airflow, bronchitis, reduced host defences, } \\
\text { diminished athletic performance }\end{array}$ & Exercise, respiratory tract infection, asthma \\
\hline Carbon monoxide & $\begin{array}{l}\text { Symptoms of mild carboxyhemoglobinemia: headache, irritability, } \\
\text { angina in some persons with coronary artery disease }\end{array}$ & Coronary artery disease \\
\hline Particulates $\left(\mathrm{PM}_{10}\right)$ & $\begin{array}{l}\text { Airways irritation, bronchitis, increased hospital admissions, overall } \\
\text { mortality from many causes, possible carcinogenicity (not proven) }\end{array}$ & $\begin{array}{l}\text { Sulphur dioxide, sulphuric acid, heat, } \\
\text { humidity, exercise }\end{array}$ \\
\hline Hydrogen sulphide & Foul odour, airway irritation & $\begin{array}{l}\text { Regional problem, especially in Alberta; } \\
\text { usually incidental release }\end{array}$ \\
\hline $\begin{array}{l}\text { Sulphates, sulphuric } \\
\text { acid }\end{array}$ & $\begin{array}{l}\text { Severe airways irritation, possibly provocation of asthmatic episodes, } \\
\text { increased hospital admissions }\end{array}$ & Particulates \\
\hline Peroxyacetyl nitrate & Eye irritation & Other aldehydes may contribute \\
\hline Lead & $\begin{array}{l}\text { Possible cumulative contribution to body burden, possible borderline } \\
\text { cognitive impairment (within overall range of normal) }\end{array}$ & $\begin{array}{l}\text { Other sources of lead; contribution of } \\
\text { airborne lead to problem is diminishing } \\
\text { rapidly since lead is no longer added to } \\
\text { gasoline }\end{array}$ \\
\hline
\end{tabular}

relevant concentrations since the 1950s. A detailed review of the toxicology of each is beyond the scope of this article. Table 3 summarizes the most significant and characteristic effects associated with each of the pollutants covered by Canadian ambient air quality objectives and some other significant pollutants. The table only lists outcomes directly related to health that are reasonably well established in the epidemiological, toxicological or clinical experimental literature at exposures that are environmentally relevant (generally near or above but not greatly in excess of the maximum acceptable levei). In the case of mortality associated with PM10, airborne levels were gencrally well within applicable air quality standards (29). There are many additional effects for each, associated with higher exposure levels, and many effects have been documented at the lissue or biochemical level (44).

There are two major 'burning' issues in air pollution toxicology at the moment: ozonc and PM10. Both will be discussed in greater detail. However, it should be noted that there are many other issues involving health effects and air quality that are under alclive investigation.

Ozone is a 'secondary pollutant', the product of photochemical reactions, some involving nitric oxide and others involving hydrocarbons, hoth of which are primary emissions. Ozone is an intensely reactive and therefore irritating gas. In recent years it has become clear that elevated ozone levels provoke asthmatic episodes, as discussed in greater detail below, although it is not so obvious that ozone could be a cause of asthma in the first place (61). It now appears to be the most critical constituent of the 'acid summer haze' effect, described in part $2(24,62,63)$. Thus, the toxicological significance of ozone in photochemical air pollution has becomc increasingly more apprecialed in recent years. The problem is that ozone is also a natural background constituent in the atmosphere, particularly in mountainous areas, at concentrations approaching one-tenth to one-half of current air quality guidelines and standards, which are themselves associated with demonstrable effects in recent studies. This means that there is much less of a potential margin of safety for ozone than for other air pollutants, but it also means that control of ozone is harder in these areas and that enforcement of tight standards may be difficult or impossible where background ozone levels are high. Control of ozone is not simply a matter of controlling emissions at an identifiable source; it involves controlling all sources of hydrocarbon release and, simultaneously, all sources of combustion emitting oxides of nitrogen. This is a formidable task. There has been good evidence for many years that health effects due to ozone can occur at or near existing guidelines and standards (64). However, it is not clear that ozone can be reasonably controlled down to a level of no effect.

The role of $\mathrm{PM}_{10}$ in causing excess mortality from respiratory and other causes (29) is a mystery. It is not al all clear what mechanism is responsible for the nonrespiratory deaths because the respiratory deaths occur at relatively low concentrations, within current air quality guidelines. Neither respiratory nor nonrespiratory mortality show a threshold response. So far, the individual risks documented in population studies have been modest but the magnitude of the effect in an entire population is unexpectedly large $(65,60)$. Evidence available to date suggests that for every $10 \mathrm{mg} / \mathrm{m}^{3}$ increase in $\mathrm{PM}_{10}$, there is a corresponding increase per day of $1 \%$ in deaths overall, $1.4 \%$ in cardiovascular deaths, $3.4 \%$ in respiratory deaths, $1 \%$ in emergency department admissions and $3 \%$ increase in use of bronchodilators by asthmatic patients (67). No threshold is apparent from their data or from other studies (66). Sorting this out will probably be the principal task in air pollution toxicology of the late $199(2 \mathrm{~s}$. 
Another aspect of air pollution toxicology is the characterization of mixed exposure. It is very common - indeed, it is usual - for more than one hazardous air pollutant to be present at the same time. In some unusual cases it is possible that two or more chemical exposures will have an interactive or synergistic effect on the body, leading to greater toxicity than would be predicted from adding up their individual effects. The problem of mixed exposure is much talked about, but in smog, an additive effect of oxidants almost always

ACKNOWLEDGEMENTS: I thank Dr John R Goldsmith for his input and collaboration on a much earlier version of this work (1983) and for providing me with the drawings that became Figures 2 through 5 in this article. I thank Dr X Chris Le for assisting in bringing my knowledge of current monitoring methods for $\mathrm{SO}_{\mathrm{x}}$ up to date. I also thank the American Lung Association of San Diego and Imperial Countries, the South Coast Air Quality Management District, the California Air Quality Advisory Committee, and the Clean Air Strategic Alliance of Alberta, which together have given me a front row seat to observe air quality issues and public policy as they have evolved over 25 years. This paper is dedicated to the memory of Dr Stan Rokaw.

\section{REFERENCES}

1. Bobak M, Leon DA. Air pollution and infant mortality in the Crech Republic, 1986-88. Lancet 1992;340:1010-4.

2. Levy B, ed. Air Pollution in Central and Eastern Europe: Health and Public Policy. Proceedings of the Second Annual Symposium on Environmental and Occupational Health During Societal Transition in Central and Eastern Europe, June 14019, 1991, Frydek-Mistek, Czechoslovakia. Boston: Management Sciences for Health, 1991.

3. Krewski D, Slovic P, Bartlett S, Flynn J, Mertz C. Health risk perception in Canada. Risk Anal 1995. (In press)

4. Decision Research. Final Report: Health Risk Perception in Canada. Portland: Decision Research, 1992.

5. California Comparative Risk Project. Toward the 21 st Century: planning for the Protection of California's Environment. Sacramento: Office of Environmental Health Hazard Assessment, 1994.

6. Vermont Agency of Natural Resources. Environment 1991 Risks to Vermont and Vermonters: A Report by the Public Advisory Committee, the Strategy for Vermont's Third Century. Waterbury: State of Vermont, 1991.

7. Blanc P, Nadel JA. Clearing the air: the links between occupational and environmental air pollution control. Public Health Rev 1994;22:251-70.

8. Goldsmith JR. The usefulness of epidemiology in environmental health protection. Atmospheric pollution effects. Public Health Rev 1991; 18:183-236.

9. Haagen-Smit AJ. The control of air pollution. Sci Am 1964;210:25-31.

10. California Department of Public Health. Clcin Air for California: Initial Report of the Air Pollution Study Project. San Francisco: State of California, 1955.

11. Haagen-Smit AJ. Chemistry and physiology of Los Angeles smog. Ind Eng Chem 1952;44:1342-6.

12. Magill PL, Benoliel RW. Air pollution in Los Angeles County: contribution of combustion products. Ind Eng Chem 1952:44:1347-51.

13. Lippmann M. Size distributions in urban acrosols. Ann NY Acad Sci 1980;338:1-12.

14. US Secretary of Health Education and Welfare. Progress in the prevention and control of air pollution: First report of the Secretary of Health, Education, and Welfare to the United States Congress pursuant to Public Law 90-148, the Air predominates and obvious interactive effects are rarely seen. The most common example of an interactive effect, especially in the past, has been the 'sulphate-particulate complex', producing the enhanced respiratory irritation observed in excess of the combined predicted effects of sulphur dioxide and particulates taken individually. However, these exposures characteristic of reducing air pollution have been largely brought under control with the exception of developing countries.

Quality Act of 1967. Washington: US Government Printing Office, 1968.

15. National Commission on Air Quality. To Breathe Clean Air. Washington: US Government Printing Office, 198I.

16. Lipfert FW. Air Pollution and Community Health: A Critical Review and Data Sourcebook. New York: Van Nostrand Reinhold, 1994.

17. Lents JM, Kelly WJ. clearing the air in Los Angeles. Sci Am 1993;269:32-8.

18. Bates DV. A Citizen's Guide to Air Pollution. Montreal: McGill-Queen's University Press, 1972.

19. Marchand L. The importance of clean air in Canada. J Air Poll Control Assoc 1979;29:104-5.

20. Bates DV. Community air pollution in Canada: a review and prediction for the 1980s. Can Med Assoc J 1979:120:1252-6.

21. Ricci P, Inhaber H, Pinchuk M. Canadian urban air yuality. 1971-1975. Atmos Environ 1978;12:2369-75.

22. Levy D, Gent M, Newhouse M. Relationship between aculc respiratory illness and air pollution levels in an industrial city. Am Rev Respir Dis 1977;116:167-73.

23. Mage DT, Gammage RB. Evaluation of changes in indoor air quality occurring over the past several decades. In: Gammage RB, Kaye SV, Jacobs VA, eds. Indoor Air and Human Health. Chelsea: Lewis, 1985:5-36.

24. Bates DV, Sizto D. Air pollution and hospital admissions in southern Ontario: the acid summer haze effect. Environ Res 1987;43:317-31.

25. Bates DV, Baker-Anderson M, Sizto R. Asthma attack periodicity: a study of hospital emergency visits in Vancouver. Environ Res 1990;51:51-70.

26. Guidotti TL. Mortality from airways disorders in Alberta, 1927-1987: An expanding cpidemic of COPD hut asthma show little change. J Asthma, 1994a;31:277-290.

27. Hoek G, Fischer P, Brunekreef B, Lebret E, Holschrcuder P, Mennen MG. Acute effects of ambient ozone on pulmonary function of children in the Netherlands. Am Rev Respir Dis 1993;147:111-7.

28. Hoek G, Brunekreef B, Kosterink P, van den Berg R, Holischreuder P. Effect of ambient ozone on peak expiratory flow of exercising children in the Netherlands. Arch Environ Health 1993;48:27-32.

29. Dockery DW, Pope CA III, Xu X, et al. An association between air pollution and morlality in six U.S. cities. N Engl J Med 1993;329:1753-9

30. Canadian Council of Ministers of the Environment. Draft Management Plan for Nitrogen Oxides $\left(\mathrm{NO}_{\mathrm{x}}\right)$ and Volatile Organic Compounds (VOCs). Ottawa: Ministry of Supply and Services, 1992.

31. Canadian Council of Ministers for the Environment. Management Plan for Nitrogen Oxides $\left(\mathrm{NO}_{\mathrm{x}}\right)$ and Volatile Organic Compounds (VOCs). Phase I: Summary Report (CCME-EPC/TRE-32E). Ottawa: Ministry of Supply and Services, 1990.

32. Yassi A, Friesen B. Controlling air pollution: the plan to reduce nitrogen oxides $\left(\mathrm{NO}_{\mathrm{x}}\right)$ and volatile organic compounds (VOCs) in Canadi. Can J Public Health 199();81:6-9. 
33. Legge AH, English M, Guidotti TL, Sandhu H. A vision of clean air. J Air Waste Manag Assoc 1992;42:888-91.

34. Guidotti TL, Conway JB. The environmental health sciences: building a faculty on basic principles. Arch Complex Environ Sys 1990;2:1-8.

35. Hesketh DA, ed. Air Monitoring Methods for Industrial Contaminants. Davis: Biomedical Publications, 1983.

36. Hallidily HE. Air Pollution ControI. Ann Arbor: Ann Arbor Science Publishers, 1979)

37. Environment Canada. Air Quality Trends in Canadian Cities, 1979-1992. Ottawa: Environment Canada, 1994.

38. Committee on Environmental Health (of the American Academy of Pediatrics). Ambient air pollution: respiratory hazards to children. Pediatrics 1993;91:1210-3.

39. Godish T. Air Quality. Chelsea: Lewis Publishers, 1986.

40. Nieuvstadt FTM, van Dop H. Atmospheric Turbulence and Air Pollution Modelling. Boston: D Reidel Publishing, 1984.

41. Calver JG, Heywood JB, Sawyer RF, Seinfeld JH. Achieving acceptable air quality: some reflections on controlling vehicle emissions. Science 1993;261:37-45.

42. Subcommittee on Public Health Aspects of Energy, Committce on Public Health. Symposium on environmental effects of sulfur oxides and related parliculates. Bull NY Acad Sci 1978;54:983-1294.

43. Finlayson-Pitts BJ, Pitts JN. Atmospheric Chemistry: Fundamentals and Experimensal Techniques. New York: John Wiley \& Sons, 1986.

44. Amdur MO. Air pollutants. In: Amdor MO, Doult J, Klaasen CD, eds. Casarett and Doull's Toxicology: The Basic Science of Poisons. New York: McGraw-Hill, 1991:854-71.

45. Speizer F. Ozone and photochemical pollutants: status after 25 ycars. West J Med 1985; 142:377-9.

46. Goldstein E, Hackney J, Rokaw S. Photochemical air pollution, Part I. West J Med 1985; 142:369-70.

47. Goldsmith JR. Los Angeles smog. Sci J 1969;5:44-9.

48. Cleveland WS, Graedel TE. Photochemical air pollution in the northeast United States. Science 1979:204:127.3-8.

49. Guidotti TL, Last J. Implications for human health of global atmospheric changes. Trans R Soc Can 1491:Ser 6, II:223-9.

50. Telang SA. Surface Water Acidification: Literature Review. Calgary: The Acid Deposition Research Program, 1987.

51. Raizenne, ME, Burnett RT, Stern B, Franklin CA, Spengler JD. Acute lung function responses to ambient acid aerosols in children. Environ Health Perspect 1989;79: 179-85.

52. Rogers R, Guidotti TL. Indoor air quality. In: Cordisco E,
Dement S, Zenz C, eds. Environmental Lung Disease. New York: Van Nostrand-Reinhold, 1995:179-208.

53. Gong H Jr. Health effects of air pollution. Clin Chest Med 1992; 13:201-14.

54. Guidoti TL. The higher oxides of nitrogen: inhalation toxicology. Environ Res 1978;15:443-72.

55. Guidotti TL, Mattson ME. Health risks associated with residence near a primary copper smelter: a preliminary report Am J Ind Med 1980;1:365-74.

56. Hopwood DG, Guidotti TL. Recall bias in exposed subjects following a toxic exposure incident. Arch Environ Health 1988:43:234-7.

57. Guidotti TL. Toxic inhalation of nitrogen dioxide: morphologic and functional changes. Exp Mol Pathol 1980;33:9()-103.

58. Voisin C, Aerts C, Wallaert B. Prevention of in vitro oxidantmediated alveolar macrophage injury by cellular glutathione and precursors. Bull Eur Physiopathol Respir 1987;23:30()- 13.

54. Mohsenin V. Effect of vitamin C on NO2-induced airway hyperresponsiveness in normal subjects: a randomized doubleblind experiment. Am Rev Respir Dis 1987;136:1408- I I.

60. Berglund M, Bostrom C-E, Bylin G, et al. Health risk evaluation of nitrogen oxides. Scand J Work Environ Hcalth 1)93:19(Suppl 2):1-72.

61. Stern BR, Raizenne ME, Burnett RT, Jones L, Kearney J, Franklin CA. Air pollution and childhood respiratory health. Exposure to sulfate and ozone in 10 Canadian rural communities. Environ Res 1994;66:125-42.

62. Linn WS, Shamoo DA, Anderson KR, Peng R-C, Avol EL, Hackney JD. Effects of prolonged, repeated exposure to ozone, sulfuric acid, and their combination in healthy and asthmatic volunteers. Am J Respir Crit Care Med 1994;150:431-40.

63. Bates DV, Sizto D. The Ontario Air Pollution Study: identification of the causative agent. Environ Health Perspect 1989;79:69-72.

(44. Bates DV. Epidemiologic basis for photochemical oxidanı standard. Environ Health Perspect 1983;52:125-9.

65. Pope CA III, Kanner RE. Acute effects of $\mathrm{PM}_{10}$ pollution on pulmonary function of smokers with mild to moderate chronic obstructive pulmonary disease. Am Rev Respir Dis 1993; 147:1336-40.

66. Schwartz J. Air pollution and daily mortality in Birmingham, Alabama. Am J Epidemiol 1993; 137:1136-47.

67. Dockery DW, Pope CA III. Acute respiratory effects of particulate air pollution. Ann Rev Public Health I) $94 ; 15: 107-32$. 


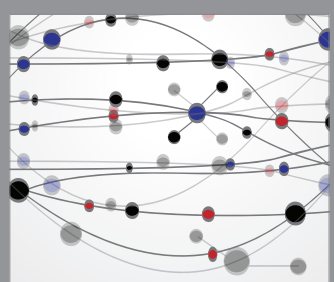

The Scientific World Journal
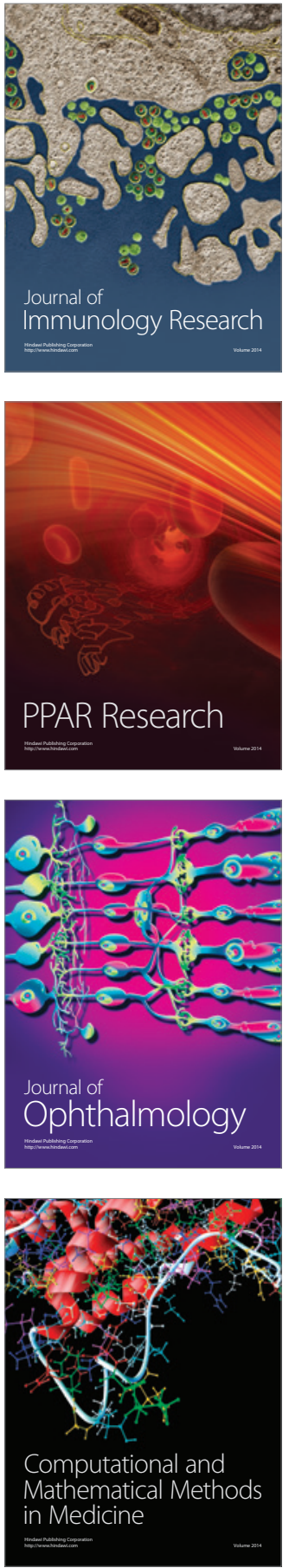

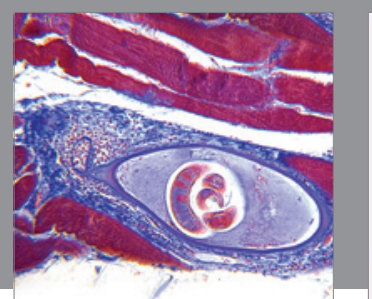

Gastroenterology Research and Practice

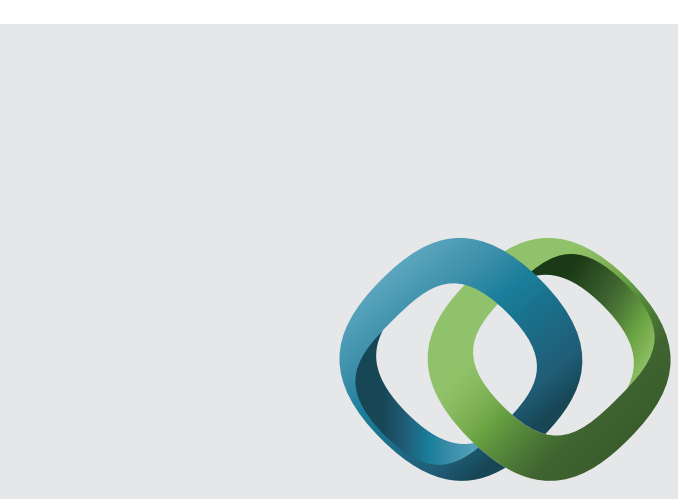

\section{Hindawi}

Submit your manuscripts at

http://www.hindawi.com
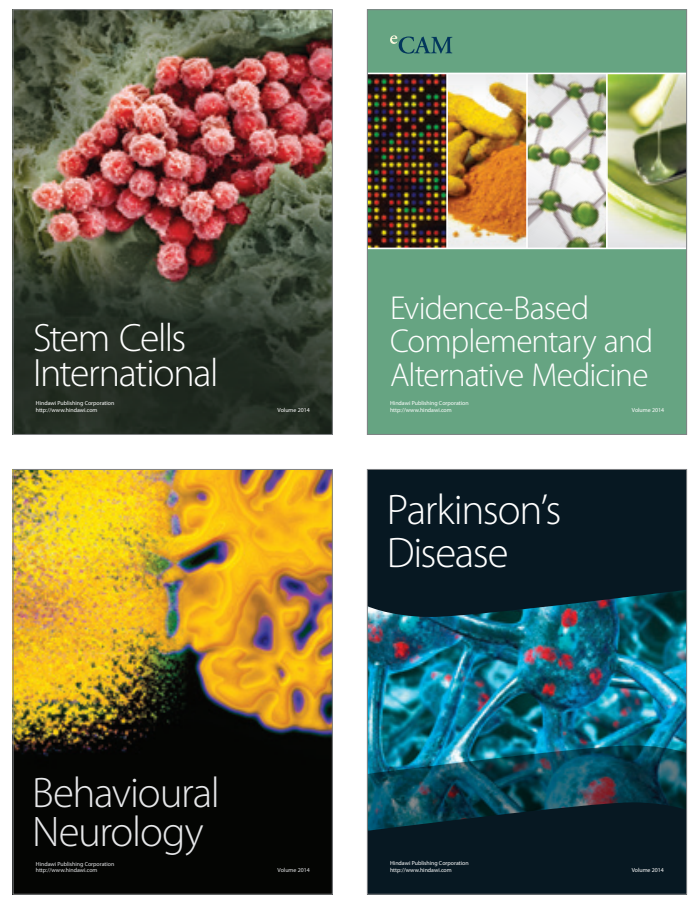
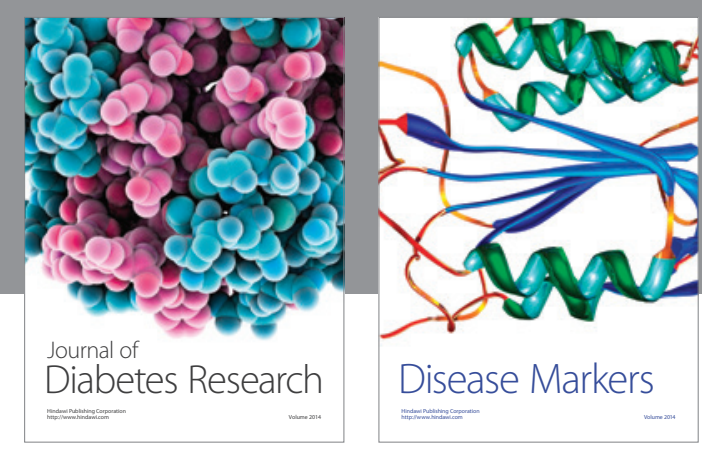

Disease Markers
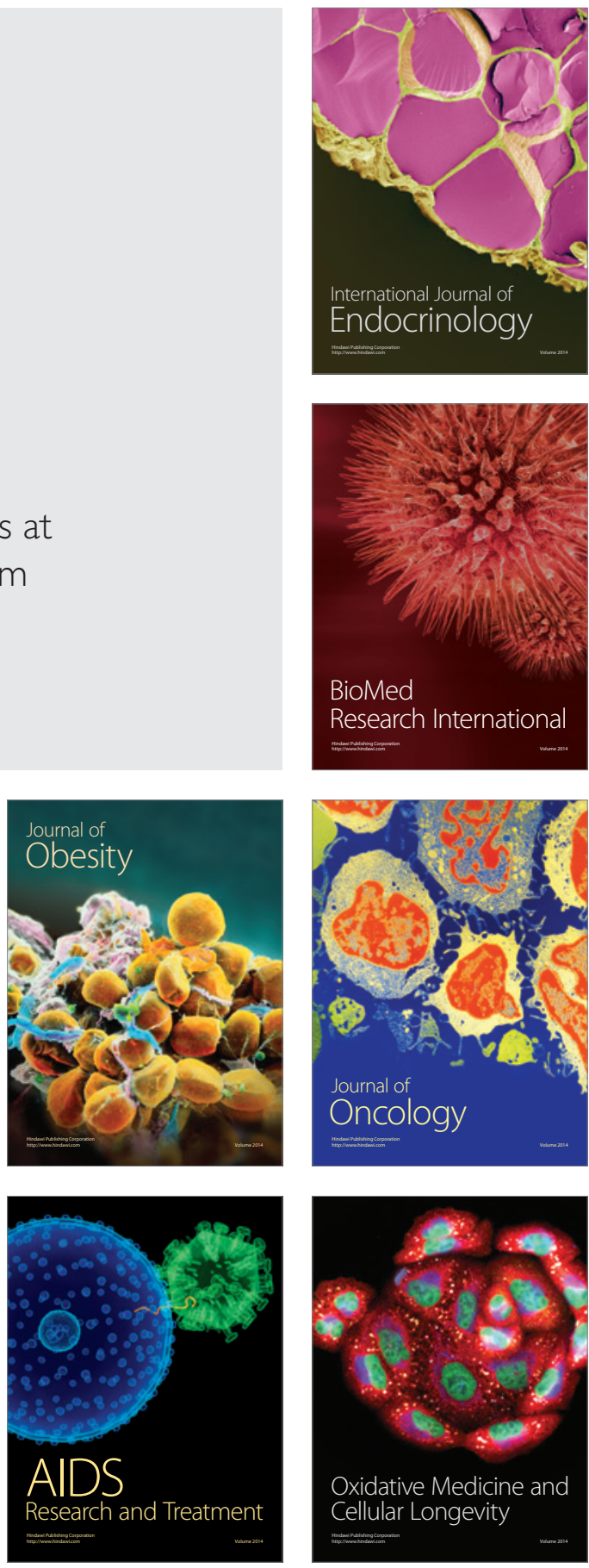